\title{
Assessment of Alluvial Aquifer Intrinsic Vulnerability by a Generic Drastic Model; A Discussion on Data Adequacy and Pragmatic Results
}

Kamal Taheri

Kermanshah Regional Water Authority

Thomas M. Missimer

Florida Gulf Coast University

Amjad Maleki ( $\sim$ a.maleki@razi.ac.ir)

Razi University of Kermanshah: Razi University

Reza Omidipour

Ilam University

Jamil Bahrami

University of Kurdistan

\section{Research Article}

Keywords: DRASTIC, Groundwater modelling, Groundwater contamination, Receiver Operating Curve (ROC), Groundwater modelling verification

Posted Date: June 7th, 2021

DOl: https://doi.org/10.21203/rs.3.rs-525916/v1

License: (c) (i) This work is licensed under a Creative Commons Attribution 4.0 International License.

Read Full License 


\section{Assessment of alluvial aquifer intrinsic vulnerability by a generic DRASTIC model; a discussion on data adequacy and pragmatic results}

Kamal Taheri ${ }^{1}$, Thomas M. Missimer ${ }^{2}$, Amjad Maleki ${ }^{3}$, Reza Omidipour, ${ }^{4}$ Jamil Bahrami $^{5}$

1-Kermanshah Regional Water Authority (KRWA), Kermanshah, Iran

2-U. A. Whitaker College of Engineering, Emergent Technologies Institute, Florida Gulf Coast University, 16301 Innovation Lane, Fort Myers, FL 33913, USA

3- Department of Geography, Geomorphology Group, Razi University, Kermanshah, Iran

4- Department of Range and Watershed Management, Faculty of Agriculture, Ilam University, Ilam , Iran

5- Civil Engineering Department, University of Kurdistan, Sanandaj, Iran

\section{Abstract}

DRASTIC is a model that is commonly used to assess vulnerability to groundwater contamination at the landscape scale. When sparse data are available to populate the layers of the model, it can be difficult to ascertain the true usefulness of the model produced map. In this research an alluvial aquifer, the Sahneh aquifer in Kermanshah province of western Iran, was mapped using the generic DRASTIC model. The data available for populating the model layers were generally sparse. The model was validated using a nitrate concentration map constructed from well water measurements within the DRASTIC map area. A Receiver Operating Curve (ROC) analysis was conducted by placing 500 random points in the DRASTIC generated map compared to the nitrate concentration map. The area under the curve was compared and yielded a value of 0.72 or $72 \%$ concordance, which means it has good validity. This investigation demonstrates that a generic DRASTIC model can yield acceptable results without modification or increasing its complexity. If the ROC analysis had yielded a value $<50 \%$, then the DRASTIC would have been considered to not be useful. A common mistake in the use of DRASTIC is to modify the method to greatly increase its complexity, which may actually decrease, not increase the resultant model usefulness.

Keywords DRASTIC - Groundwater modelling · Groundwater contamination · Receiver Operating Curve $(\mathrm{ROC}) \cdot$ Groundwater modelling verification 


\section{Introduction}

The DRASTIC model has been evaluated to assess both its advantages and disadvantages for use in groundwater pollution management (Aller et al. 1987). Despite the criticisms of the model by various researchers, it is still one of the most popular and widely used methods for assessing aquifer contamination potential (Rundquist et al. 1991; Al-Adamat et al. 2003; Babiker et al. 2005; Baalousha 2006; Moghaddam and Fijani 2008; Hamza and Added 2009; Kura et al. 2015; Vaezihir and Tabarmayeh 2015; Muhammetoglu et al. 2019; Ghosh et al. 2020; Torkashvand et al. 2020; Mallik et al. 2021; Nasri et al. 2021). The simplicity and usability of the DRASTIC model allows it to assess vulnerability of an aquifer to pollution even where sparse data are available on aquifer hydrogeological characteristics. From a terminological point of view, the choice of the word DRASTIC for the seven acronyms that assess intrinsic vulnerability is interesting and thought-provoking, because the word itself has a strong meaning and indicates a situation that should be considered (Dictionary, C 2008).

Despite the apparent simplicity of the seven factors in the DRASTIC model, development and presentation of thematic and practical maps with accurate data (or at least sufficient) is not so easy. While DRASTIC is a simple and restrained method that gives results in any case, the adequacy of the data and the realism of the results can make the output of this model sufficiently reliable for use by local planners and decision makers. However, the use of the model results must be constrained within the famous statement that "All models are wrong, but some are useful; the practical question is how wrong they have to be to not be useful." (Box and Draper 1987). The statement by Box and Draper (1987) applies not only to the accuracy of the model, which is commonly controlled by the input parameters (data), but also applies to how the model is applied with consideration of the error framework.

The simplicity of the DRASTIC model is the evaluation methodology and use of specific weights and rates as suggested by Aller et al. (1987). Advancements in software development now make it is possible to easily overlap the seven layers within a GIS framework and obtain a digital output that can be categorized in different ways. In this regard, there are numerous articles that have provided various classifications for the final model-generated map, from non-vulnerability (Metni et al. 2004; Herlinger and Viero 2007; Prasad et al. 2011; Chitsazan and Akhtari 2009; Yin et al. 2012) to extreme vulnerability (Rozkowski 2010; Herlinger and Viero 2007). Different input parameters used to create the final map can be varied depending on the needs of the different users. The sum of the seven DRASTIC parameters yields a 
generic DRASTIC index with the highest numbers corresponding to the highest vulnerability to contamination (Corniello et al. 1997; Hua et al. 2011).

Hamza et al. (2015) concluded, based on a compilation of 30 studies that computed the DRASTIC index and vulnerability classifications, that the generic index values range between 23 and 230. They suggested that to calculate the percentages within the vulnerability classes, a simple formula could be used (Equation 1).

$$
(\mathrm{i} / 230) \times 100
$$

where $\mathrm{i}$ is the index range. The classification of vulnerability reported in the various investigations included no risk, very low risk, low risk, medium risk, high risk, very high risk, and extreme risk. Only 7 of the 30 studies showed any area within the no risk classification and only 2 of the 30 studies showed any area within the extreme risk classification (Hamza et al 2015).

Some researchers believe that "no risk" as one of the final map categories is basically incorrect because any aquifer can be inherently vulnerable to pollution, even if the vulnerability was very low (Hamza et al. 2015). The main flaw within the DRASTIC method lies in the adequacy of the data, i.e., how and from what sources are these data obtained or extracted? Can lack of data in one or more of the primary DRASTIC parameters be ignored in the absence of better quality data in some other parameters? To what extent can modification of the model increase the public acceptance of the model results? Is it useful to add additional layers to this model? How can data differentiation increase the realism of the results? What can be done in the absence of data to validate the model? This goes back to the fundamental question posed by Box and Draper (1987) “All models are wrong, but some are useful; the practical question is how wrong do they have to be to not be useful."

The answer to all of these questions lies in the ability of the researcher(s) to extract or provide adequate data and to perform sufficient analyses on the model output results to provide a reasonable degree of assurance that the model is useful. To produce an accurate vulnerability assessment, the researcher must be familiar with the basic principles of hydrogeology. It is very important to understand the nature of various units constituting and affecting the aquifer from the unsaturated zone to the base of the aquifer. In addition, there are fundamental relationships between some of the seven DRASTIC parameters that need to be considered, such as the soil media and the aquifer media may be the same when the water table occurs at 
or near land surface. There is also a close relationship between impacts occurring within the vadose zone and the soil media. For example, it is possible to provide a single layer based a few water drilling logs for the impact of the aquifer media and the vadose zone. If the nature of the upper part of aquifer system is over-simplified by ignoring the occurrence of a clay or gravel unit, the results of the DRASTIC assessment could be inaccurate. This issue is quite extreme in karst environments, where flow conduits could provide a bypass through which contaminants could directly enter deep into an aquifer (Taheri, et al. 2017).

Application of the DRASTIC model could be used in basic educational for students of hydrogeology, groundwater and related disciplines (Rich and Onasch 1997). Because preparation of the database for the seven factors involves all the principles and methods of theory in the field of groundwater. Presenting an acceptable result and preparing seven parameters with sufficiently accurate data can indicate the adequacy of knowledge on the aquifer being investigated and the perspective for its optimal management. In operational and executive terms, if an acceptable output can be obtained with a DRASTIC model in an aquifer, it can be hoped that at least the groundwater management infrastructure is available in that area. Because a first step in managing an aquifer may be to have a map of the vulnerability of that aquifer (Merchant 1994). Considerable research has been conducted on different technical aspects and applications of the DRASTIC model (Merchant 1995; Shirazi et al. 2012; Hamza et al. 2014; Khosravi et al. 2018; Kumar et al. 2019; Barbulescu 2020).

In this research, the Sahneh aquifer in the Kermanshah province of Iran was evaluated using the method of Aller et al. (1987) based on their proposed weights of the DRASTIC parameters. The results were evaluated by developing a critical assessment of the advantages and disadvantages of the output and methodology. This evaluation was achieved by assessing the accuracy of the available data for each DRASTIC parameter. The results of the DRASTIC model output were then compared with an expert-centered scoring method applied to the same land area. This comparison was used to evaluate the real variability in the DRASTIC model outputs to illustrate the potential errors with the assessment and how the output should be used within the context of groundwater management. A test of the model validity was used to ascertain its usefulness by using nitrate data with the context of a Receiver Operating Curve analysis (ROC). This research provides a method to review the generic DRASTIC method and validation of its outputs to create a practical guide to water managers on the usefulness of the model and what restrictions should be placed on the output use. 


\section{Study area}

The study was conducted on the Sahneh aquifer that is located mainly in the Sahneh Subcatchment in the Kermanshah province of western Iran (Fig. 1a). The Sahneh aquifer covers a relatively small area that is located in a cold and dry region (Fig. 1b,c). This aquifer is located in the structural zone of Sanandaj-Sirjan and thrust fault zone of Zagros. The behavior of the aquifer geological units is a function of the structural conditions of these two zones (Fig.1e). The geological units of the region can be categorized into karst and non-karst units. Karstic units generally control the altitude of the region. In addition, the carbonate units have the most impact on the aquifer system recharge and discharge, although no detailed investigations of those factors has been made. Non- karstic units have little effect on hydraulic exchanges with the aquifer system based on aquifer hydraulic properties and the area of their occurrence. In this study, the alluvial unit is considered separately from the karst units and its hydraulic exchanges are ignored. This neglect of karst exchanges is common even in the study of the water balance by water management organizations in the region. To eliminate the karst effect in the water balance, the rate of precipitation recharge in the mountains has been added to the water balance equations. Fig. 1f summarizes the groundwater aquifer balance of the scene aquifer. 

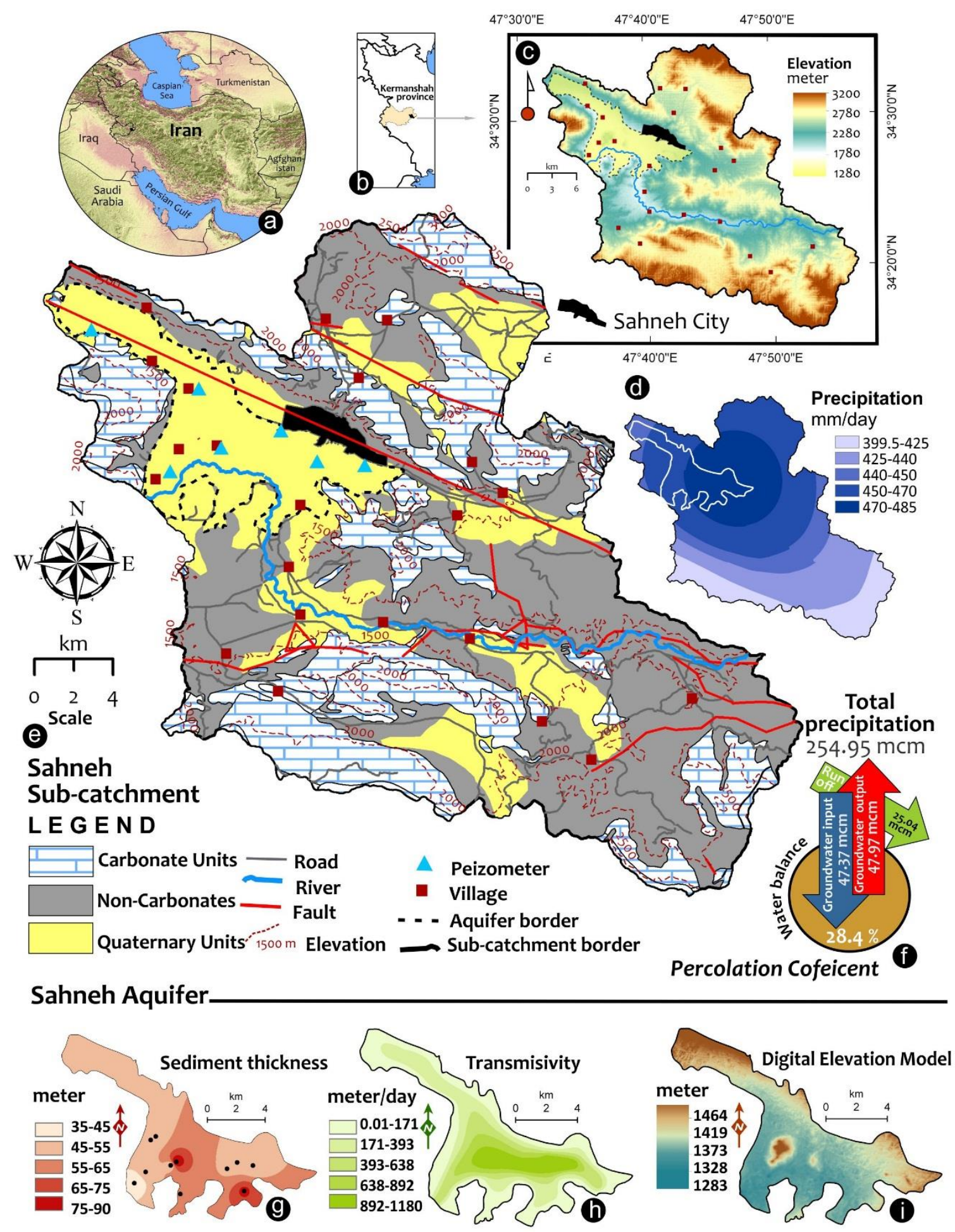

151 Fig. 1. The location of studied area in Iran (a), Kermanshah province (b), and Sahneh Sub152 catchment (c), isohytal map (d), simplified geological map and distribution of carbonate, non153 carbonate formations and porous media (plain) and alluvial aquifer boundary (e), water budget 154 summary(f), sediment thickness map (g), transmissivity map (h) and digital elevation model (i). 
Hydrogeologic assessment of the Sahneh aquifer was performed using data extracted from the seven monitoring wells. Although this number is insufficient, however, no action has been taken to correct it. Few exploratory studies of the aquifer have been conducted. The primary source of knowledge on the aquifer and its subsurface media comes from the logs of private wells used for water supply. Water levels compiled into hydrographs indicate that the groundwater balance is negative, meaning that the discharge rate is higher than the aquifer recharge rate (declining water levels) (Fig. 1f). According to the results of the water balance analysis, the recharge rates in the alluvium and higher altitudes are 3.36 million cubic meters/year (mcm) and $69.05 \mathrm{mcm}$ equivalent to $4.64 \%$ and $95.36 \%$ of the total recharge from precipitation to the sub-catchment area (water budget area), respectively. With a infiltration rate of $28.4 \%$, this means that from the total volume of rain (Fig. 1d) that falls on the alluvium, only $28.4 \%$ of this amount reaches the water table and is practically equivalent to the volume of the aquifer recharge annually. It is known that equating the infiltration rate to the recharge rate in an arid region likely overestimates recharge or underestimates infiltration. In many alluvial aquifers of Iran, the balance is done in this way, except in limited cases where detailed or case studies have been made, the infiltration rate and net recharge of the aquifer are quite approximate. Fig. 2 presents the conceptual model of the aquifer and the effective components in evaluating the DRASTIC model.

\section{DRASTIC method}

This research examines the DRASTIC method for the intrinsic evaluation of in an alluvial aquifer to assess groundwater pollution potential. The DRASTIC index is obtained based on the method of Aller et al. (1987) using the sum of the seven factors after multiplication of the weighting factors (Equations 2 and 3).

$I_{\text {DRASTIC }}=\sum_{i=1}^{7} W i \times R i$

where $\mathrm{W}_{\mathrm{j}}$ is the weighting of each parameter and $\mathrm{R}_{\mathrm{j}}$ is the corresponding rate.

$\mathrm{I}_{\text {DRASTIC }}=\left(\mathrm{D}_{\mathrm{w}} \times \mathrm{D}_{\mathrm{i}}\right)+\left(\mathrm{R}_{\mathrm{w}} \times \mathrm{R}_{\mathrm{i}}\right)+\left(\mathrm{A}_{\mathrm{w}} \mathrm{x} \mathrm{A}_{\mathrm{i}}\right)+\left(\mathrm{S}_{\mathrm{w}} \times \mathrm{S}_{\mathrm{i}}\right)+\left(\mathrm{T}_{\mathrm{w}} \times \mathrm{T}_{\mathrm{i}}\right)+\left(\mathrm{I}_{\mathrm{w}} \times \mathrm{I}_{\mathrm{i}}\right)+$

$$
\left(\mathrm{C}_{\mathrm{w}} \times \mathrm{C}_{\mathrm{i}}\right)
$$

The variables are: Depth to water (D), Net recharge (R), Aquifer media (A), Soil media (S), Topography (T), Impact of vadose zone (I), and Hydraulic conductivity (C). Each factor was calculated by multiplying the weight by the rate of that factor. 
The importance and explanation of the seven factors and its conceptual model based on 187 Aller et al. (1987) are presented in Fig. 2a,b,c. It should be noted that a complete understanding 188 of the study area is the first step in the feasibility of using a DRASTIC model. As more 189 accurate information and data are provided, the DRASTIC model outputs will be more 190 accurate, functional, and better suited for use in water management. 


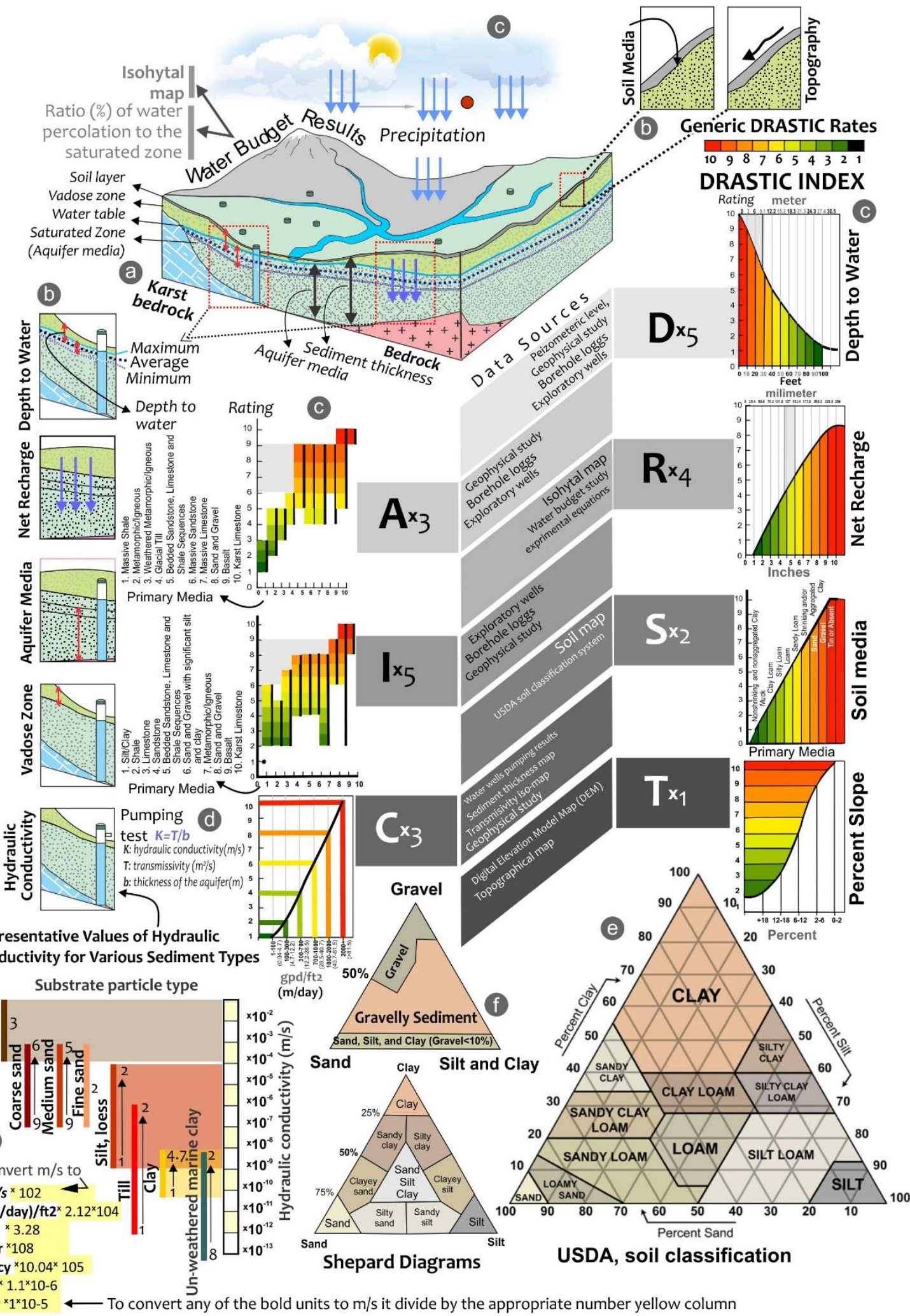

Fig. 2. a) Conceptual model of the Sahneh aquifer and important components in the evaluation of the DRASTIC model, b) seven parameters of the DRASTIC index, c) generic DRASTIC model rates for seven factors, d) pumping test components, e) USDA Soil classification, f) 
Separd diagrams, g), Representative values of hydraulic conductivity for various sediment types, and h) Unit conversions ( Domenico and Schwartz 1990).

\section{Depth to Water Table (D)}

It is defined as the vertical distance from land surface to the water table (Fig. 2a). In porous media, a groundwater depth map can be constructed by using the groundwater levels measured in piezometers in relationship to land surface altitudes (creation of a potentiometric surface maps). To obtain groundwater depth, the multi-year average of water levels in piezometers at the highest and lowest positions was calculated. From the average water level in the piezometers, a groundwater depth map was prepared. Since this study was performed on an unconfined aquifer, most of the analysis and methods are focused on this type of aquifer. In some areas where geophysical surveys were conducted, a more accurate map was obtained by combining the results of the measured water levels and geophysical surveys. In the DRASTIC method, the theoretical weight of this factor is 5. Figs. 3a and $2 \mathrm{c}$ show the groundwater depth of the Sahneh aquifer in relation to those proposed by Aller et al. (1987). The most important issue in preparing this factor is the lack of geophysical data and high degree of approximation between points of actual measurement in the piezometers.

\section{Net recharge $(\mathbf{R})$}

It is the quantity of water from infiltration and through vertical percolation penetration that reaches the zone of saturation (passes through the water table). Different methods have been proposed by different researchers to evaluate net recharge (Williams and Kissel 1991; Piscopo 2001; Hamza et al. 2007; Karan et al. 2018). The use of these methods requires minimal data related to actual infiltration. Since measurements of the relationship between infiltration and recharge do not exist, it was assumed that the recharge estimated from the water balance and the infiltration rate are approximately equal (Taheri et al. 2017). In this method, by using the multiplication curves of the rainfall percentage (from the isoheytal map) (Fig. 1d), the infiltration rate into the aquifer can be obtained with a good approximation. Fig. 3a shows the net recharge map and Fig. 2c illustrates the related rates.

\section{Aquifer media (A)}

Aquifer media is one of the most important parts of the study by the DRASTIC method. Preparing a map with good accuracy can give the final DRASTIC greater credibility and 
usefulness. The best way to map the aquifer media is to use the results of geophysical surveys and match it with the results of exploratory geologic well logs. In the absence of these two data sources, information was used from public water well drilling logs with a high degree of distribution in the aquifer area.

To prepare the map of the aquifer media layer, the type of sediment above and below the water table was determined using statistical analysis and sedimentological diagrams. By assigning numerical codes to each of these types of sediments, it is possible to interpolats and prepare a sediment distribution map. In this study, the sediment diagram of Shepard (1954) was used to classify sediments and prepare a map of the aquifer and vadose zone (Fig. 2f, 3b). Because it is practically difficult to separate clay and silt in the desert sediments, instead of separating these two factors, clay and silt were aggregated into a single class and gravel was added as the third factor. This change in the naming triangle is more applicable to aquifers and unsaturated sediments, although it may not be accurate in terms of sedimentologic laboratory studies.

\section{Soil media (S)}

The soil media occurs at the top of the system and controls the infiltration of water into the unsaturated zone and ultimately the recharge of the aquifer to some degree (Fig. 3a). Permeable soils facilitate higher rates of water infiltration and fine-grained soils produce more runoff. In many places, soil maps are available that were produced by organizations related to agriculture and soil science. In this study, the soil map of Iran was used within the context the U. S. Department of Agriculture (USDA) sediment classification (Fig. 2e). This classification was applied, because it is the standard used by many organizations that are involved in soil mapping. It is known to provide an accurate set of soil properties.

\section{Topography $(T)$}

The topography is defined in the generic DRASTIC documentation as the slope and variability in the slope of land surface. The most important effect of this factor is that the slope can cause runoff due to rainfall or cause water to remain on the ground. Ponded water on relatively flat soil surfaces can enhance infiltration and recharge (Maliva and Missimer 2012). Steep-sloped areas have enhanced runoff that lessens the potential for water infiltration. In the generic DRASTIC documentation, slopes $>18 \%$ have virtually no infiltration. This layer can be considered the most accessible layer in Iran because many researchers use the available digital 
elevation models and the GIS environment to convert the DEM (digital elevation model) layer into a slope layer (Fig. 1i, 2b, 3a).

\section{Impact of vadose zone media (I)}

Aller et al. (1987) consider the impact of the vadose zone important and have assigned the highest weight (i.e., weight of 5) to this layer and the groundwater depth layer. The vadose zone can be very influential in the end result of the model. To prepare this layer, similar to the depth layer of the aquifer, the geologic logs of private wells were used with the interpretation that the sediments above the water table were considered. (Fig. 3b). Some researchers use soil maps in the absence of data for the aquifer vadose zone. However, soil maps contain rather generic descriptions of the lithologic soil properties. The soil profiles described in the maps can be considered up to $2 \mathrm{~m}$ in depth based on the DRASTIC model. In aquifers where the water table depth is $>2 \mathrm{~m}$ below land surface, the use of soil descriptions associated with the soil maps is not accurate enough to populate the model layer.

\section{Hydraulic conductivity (C)}

It is the last layer in the seven layers of the DRASTIC model. Hydraulic conductivity refers to the ability of aquifer materials to transfer water through porous media or is the proportionality coefficient in Darcy's Law. Higher hydraulic conductivity indicates the potential to allow greater water movement in the aquifer. Hydraulic conductivity data were obtained from the results of pumping tests, slug or withdrawal tests, and some borehole geophysical methods. The best way to prepare this layer is to use the data obtained from the results of aquifer pumping tests by the organizations in charge of water and reports published by consulting engineers or geologists associated with a variety of water projects. These data have been published in the form of thematic maps for water balance studies and aquifer prohibition (Fig. 1d, 3c). In the absence of these data, Aller et al. (1987) have presented a proposed table on the basis of which hydraulic conductivity values can be estimated (Freeze and Cherry, 1979) (Fig. 1g, h). However, using geophysical test data and the portability and thickness of the aquifer, a hydraulic conductivity layer can be obtained. In this study, average hydraulic conductivity was obtained by dividing the transmissivity layer by the aquifer thickness (Fig. 1g, 1h). The hydraulic conductivity of the aquifer was computed using equation 4:

$$
k=T / b
$$


where $\mathrm{k}$ is the hydraulic conductivity of the aquifer $(\mathrm{m} / \mathrm{s}), \mathrm{T}$ is the transmissivity $\left(\mathrm{m}^{2} / \mathrm{s}\right)$, and $\mathrm{b}$ is the thickness of the aquifer $(\mathrm{m})$.

290 Groundwater experts in Iranian regional water companies and experienced drilling supervisors have provided useful information on hydraulic conductivity.
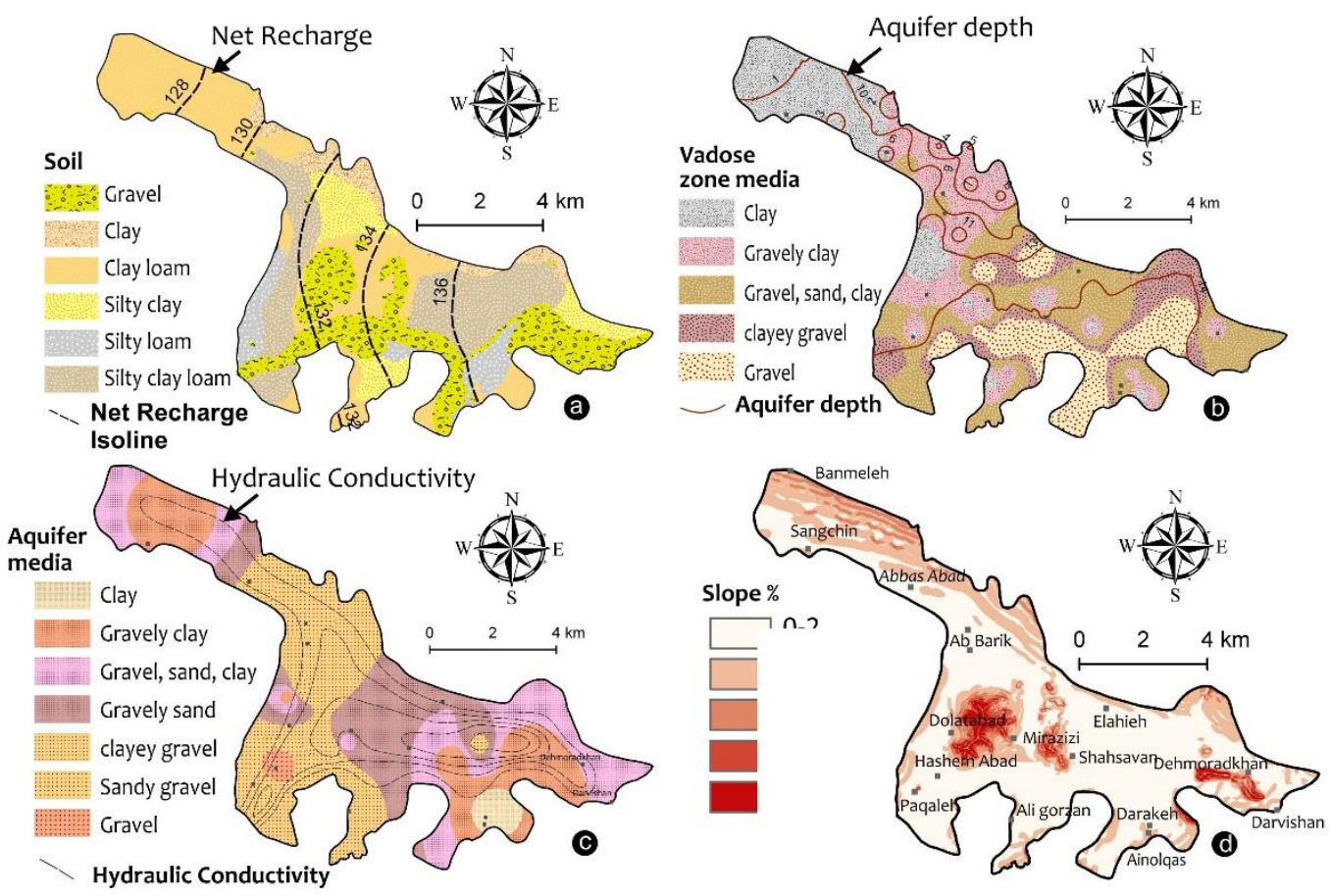

Fig. 3. Seven layers of DRASTIC model; a) soil media, and net recharge, b) vadose zone media, and aquifer depth, c) aquifer media, and hydraulic conductivity, and d) slope map.

\section{Validation and sensitivity analysis}

296 Various methods have been developed and used by researchers in order to validate DRASTIC model outputs, and to assess model sensitivity (Benesty et al. 2009; Mogaji and San Lim 2017; Kumar and Pramod Krishna 2020; Lodwick et al. 1990; Gogu and Dassargues 2000; 299 Napolitano and Fabbri 1996). The purpose of these evaluation methods is to test the adequacy 300 of the data and the final results of the model to show whether the output of the work is reliable 301 for later uses or not. Among all the published evaluation methods, the use of nitrate to assess 302 the model validity is very common (Javadi et al. 2011; Shirazi et al. 2012; Fijani et al. 2013). 303 Generally, nitrate is absent in subsurface waters and its presence indicates anthropogenic 304 influence. Therefore, groundwater nitrate concentrations were used in this study to validate the vulnerability models (Malik et al. 2021). The importance of model validation with nitrate 
stems from the fact that nitrogen is essential for plant growth and nitrate chemical fertilizers are used to produce more crops on agricultural land (Schröder et al. 2004). In the absence of nitrate data, some researchers have used other chemical parameters, such as chloride and electrical conductivity (salinity) (Sahoo et al. 2016; Salek et al. 2018).

Various organizations in Iran charged with the collection of groundwater quality data may also have available nitrate data, but the availability of these data is limited, because they are considered to be confidential. However, the nitrate concentrations have been measured in water pumped from public water wells in the area. Thereby, it was used to evaluate the model output. In this study, nitrate data was used to calibrate the model based on 50 samples collected and analyzed from rural drinking water wells. Some researchers have suggested the use of Emergent Organic Compounds for calibration (Hamza et al. 2014). No reports or published papers have been found to document this calibration method.

Among the various criticisms leveled at the DRASTIC method, three have received much attention. The first issue is whether it is necessary to use all seven proposed layers for an aquifer evaluation. Another issue is whether the weights and rates suggested by generic DRASTIC are appropriate for the study area or should be they changed to meet local conditions. Third, is whether it is necessary abandon the generic DRASTIC method and do the evaluation with a modified DRASTIC method or another model

Conducting a sensitivity analysis with a different approach is one method that can be used in response to the first and second issues. Sensitivity analysis was done to evaluate the influence of the assigned rates and weights of each class and thematic layer on the output of the aquifer vulnerability potential map since weights and ratings used in the model are theoretical, and there is a general absence of supporting experimental evidence (Napolitano and Fabbri 1996). Modified DRASTIC model approaches have received much attention in response to the third question (Baghapour et al. 2016; Soyaslan 2020; Rajput et al. 2020; Berhe Zenebe et al. 2020). Involvement of regional factors such as land use or special features such as sinkholes support changing the nature of the use of the DRASTIC model (Taheri et al. 2017; Warren 2019). For example, Mimi and Madi (2012) developed a modified method that applies to karst areas. In using the modified methods, it is important for the researcher to reach the conclusion that acceptable results cannot be achieved by using the generic DRASTIC model and that the final map contradicts the nitrate content or another evaluation parameter. If there is no contradiction, modifying the model is just an extra, perhaps unnecessary, task. 
Two common types of sensitivity analysis have been used by various researchers to evaluate the DRASTIC modifications and the impacts of needing all seven parameters to provide a useful evaluation, including map removal sensitivity and single parameter removal. Map removal sensitivity is used to examine the impacts of removing any one of the thematic layers used for the computation of the groundwater vulnerability map (Lodwick et al. 1990) by using equation 5

$S=\left(\left|\frac{\frac{V}{N}-\frac{v}{n}}{V}\right|\right) \times 100$

where $\mathrm{S}$ is the sensitivity measure expressed in terms of a variation index, $\mathrm{V}$ and $\mathrm{v}$ are the unperturbed and the perturbed vulnerability indices, respectively, and $\mathrm{N}$ and $\mathrm{n}$ are the number of data layers used to compute $\mathrm{V}$ and $\mathrm{v}$, respectively. This method has been used for other studies that are also related to groundwater or natural hazards evaluation (Taheri et al. 2020).

Single parameter removal sensitivity analysis examines the impact of each parameter on the final vulnerability map. The effective weight in this method can be estimated using the equation 6

$$
W=\left(\frac{P r \times P w}{V}\right) \times 100
$$

where $\mathrm{W}$ refers to the 'effective' weight of each parameter, $\mathrm{Pr}$ and $\mathrm{Pw}$ are the rating values and weight of each parameter, respectively, and $\mathrm{V}$ is the overall vulnerability index (Napolitano and Fabbri 1996).

If the generic DRASTIC model has applicability and produces logical results after validation, there is no need for sensitivity analysis. In some studies, some parameters do not have significant variation in the region (for example, the net recharge layer in this study, which includes only two categories). Therefore, such layers are well-defined in the sensitivity analysis with a minimal error range. During validation and sensitivity the model designer/researcher is able to determine which layer(s) are not really effective due to lack of data or lack of significant impact on the final result of the model. However, many reviewers of articles and journals consider sensitivity analysis to be a research necessity.

\section{Results}


365 Based on the data available in Kermanshah Regional Water Authority (KRWA) and its 366 affiliated departments as well as general soil maps of Agriculture Organization and 367 Climatology office of the Meteorological Organization, seven maps required for the 368 DRASTIC model were prepared (Figures 3a,b,c,d and 4). These maps provide the most 369 accurate output possible based on the available data. However, these maps are interpolated 370 with minimal data and require much more basic studies, such as geophysics, pedological 371 studies, and field measurements to improve their accuracy. Not only is it not possible to 372 provide more data at this time, but it is also unlikely for the next 10 years, based on the trend 373 of routine studies being conducted in the region. Accordingly, one of the goals of this research 374 was to check the adequacy of the results based on the available data. Data processing, data 375 sources and evaluation methods are provided for each parameter as summarized in Fig. 2.

376 By overlying the seven weighted layers, the final aquifer vulnerability map was prepared 377 (Figs. 4, 5a). The range of the calculated values was from 107 to 175, and they were divided 378 into 5 categories based on the equal interval classifier method in GIS. By applying the equal 379 interval classifier on the final map, it was divided into 5 classes, which are very low (107380 121), low (121-134), moderate (134-148), high (148-161), and very high (161-175) (Fig. 5b).

381 The results show that only $8.6 \%$ and $6.7 \%$ of the study area fall under very low and low 382 vulnerability class, respectively. The moderate and high vulnerability classes cover $26 \%$, and $38317.2 \%$ of the total study area. Most of the area, consisting of $42 \%$, is classified as having high 384 vulnerability (Fig. 5a,b). The southern part of the study area falls under the very high 385 vulnerability class and most parts of the flood plain environment occur in the very high 386 vulnerability class. Most of these areas are lands used for agricultural (crops) and rangeland 387 (grazing). Most industrial and residential areas are located in moderate vulnerability class. 


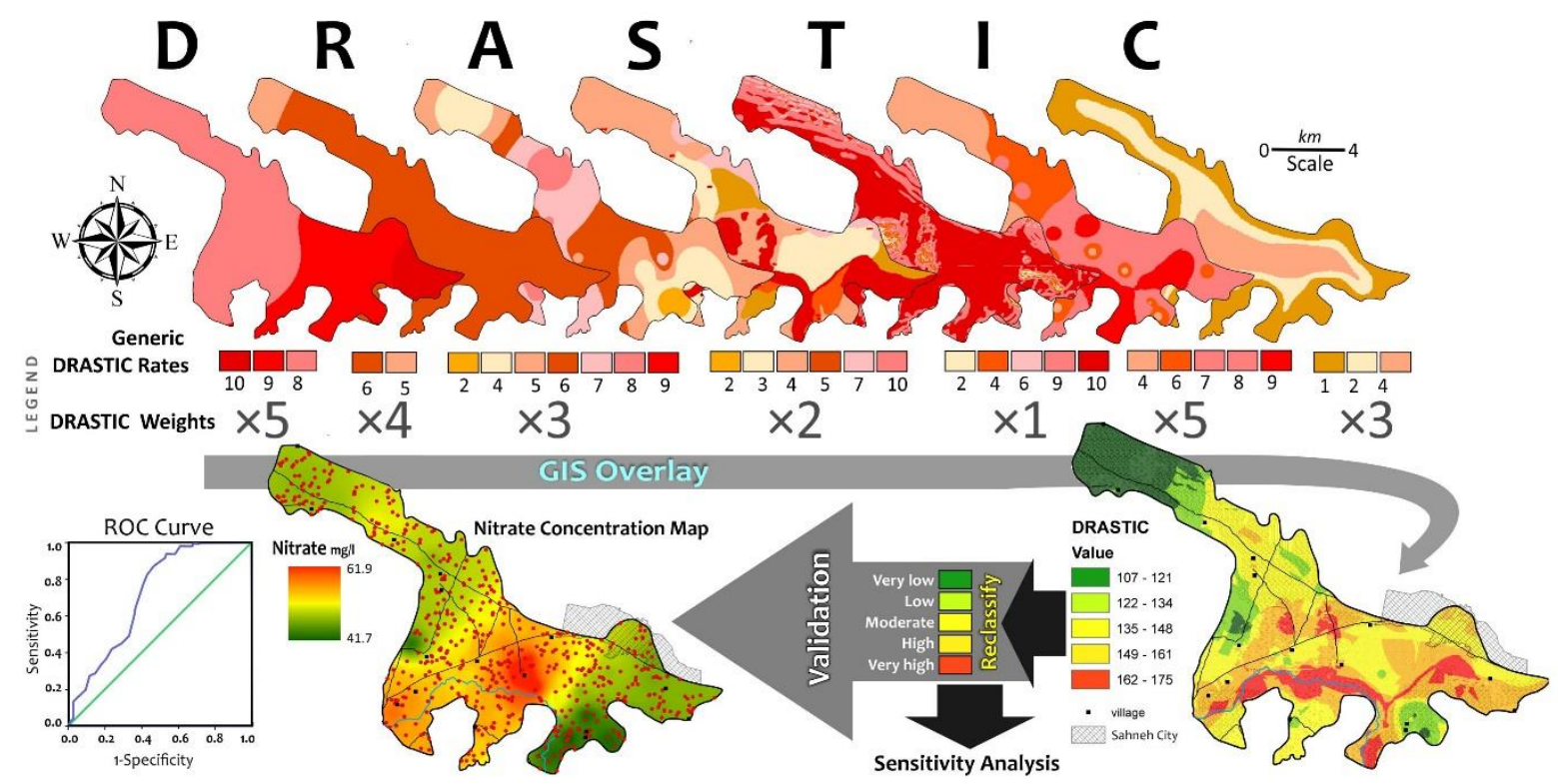

Fig. 4. Flowchart of the final output model of the general DRASTIC model in the study area

391 In this study, using the analysis of drinking water wells, the nitrate concentration in water produced from these wells was mapped in the GIS environment (Fig. 5b). There are several ways to validate the DRASTIC map using the concentration of nitrate as a proxy. The first method is to use linear regression between some or all pixel values to assess the correlation between nitrate and vulnerable zones. Another method is overlying the two maps in software environments such as Idrisi, which shows the degree of correlation (Fig. 5e). Another one of the validation methods used in many research papers in various fields including evaluation of landslides, groundwater and other sciences is the Receiver Operating Curve (ROC) curve (Chen et al., 2018; Taheri et al. 2019, 2020).

The ROC method is commonly used to assess validity of modeling results in water resources management (Khosravi et al. 2018). ROC is considered to be an evaluation of a binary classification system whose detection threshold is also variable. In this method, the accuracy of the prediction as well as the quality of the created model is evaluated based on the area under the curve (AUC). The ROC method was used to assess the validity and usefulness of the created DRASTIC model. To do this, 500 random points were placed within the map grid using GIS (Fig. 5c). The data corresponding to these points for both the nitrate concentration map and the final DRASTIC vulnerability map were assesed. For more nitrate 
concentrations greater than the standard limit of $50 \mathrm{mg} / \mathrm{L}$ a value of 1 was assigned and a

409 value 0 of was assigned to the points below the nitrate limit. Using SPSS software, the 410 characteristic curve of the graph was created. In this method, a curve showing above 50\% 411 indicates the validity of the model, and the higher the value, the more valid the model. 412 Yesilnacar and Topal (2005) classified AUC values with respect to prediction accuracy into 5 413 quantitative ranges, which are $0.5-0.6$ for low/poor, $0.6-0.7$ for moderate/average, $0.7-0.8$ for 414 good, 0.8-0.9 for very good, and 0.9-1 for excellent. Based on this approach in this study 415 AUC value obtained was 0.72 or $72 \%$, which is considered to be good validity (Fig. 5d).

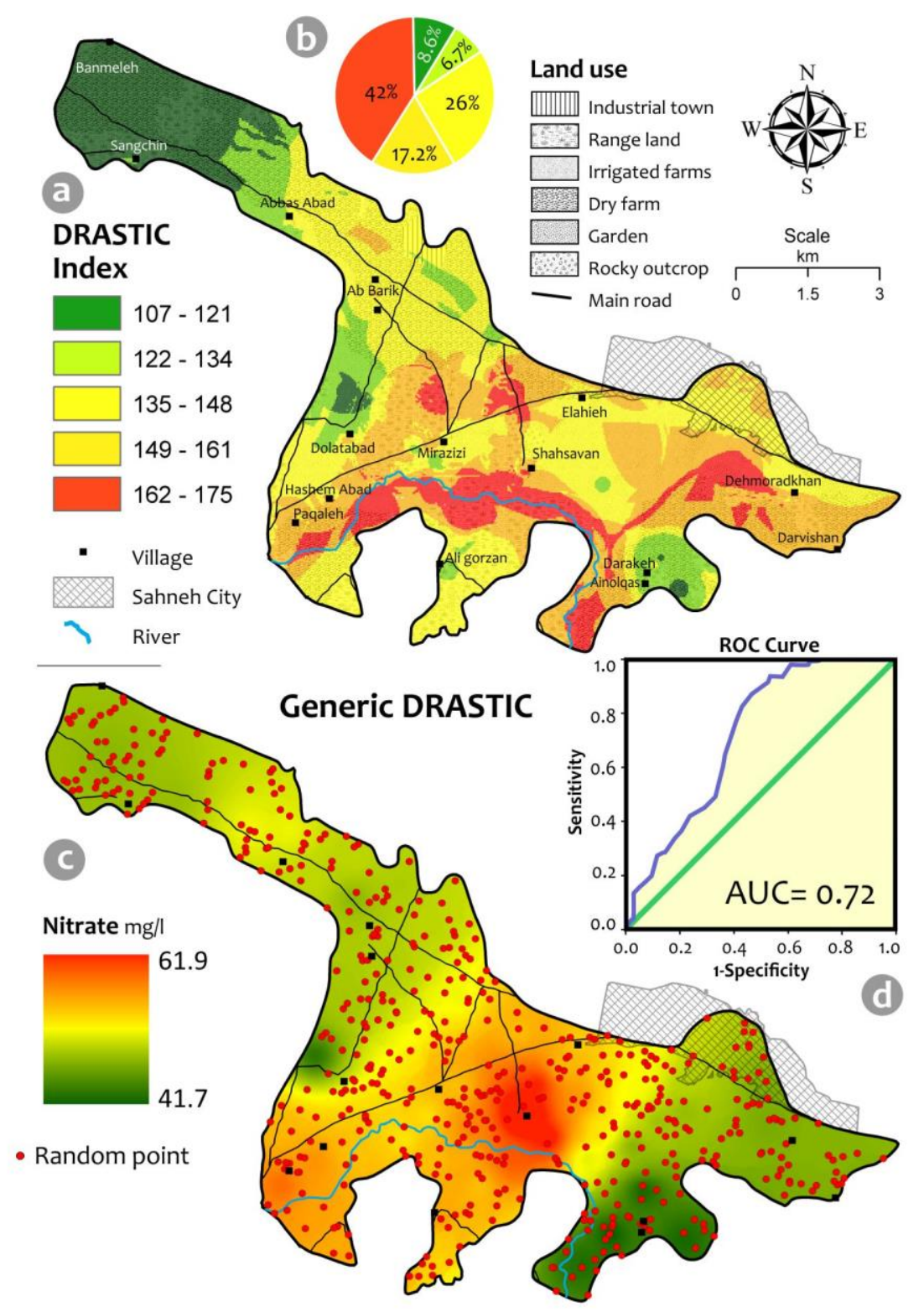


Fig. 5. Nitrate analysis results (a) and its adaptation to general DRASTIC model (b) and DRASTIC with expert weights (b) linear regression (c) ROC curve with 500 random points (d) and Idrisi output (e).

\section{Discussion}

\section{Validation and usefulness of the DRASTIC model map}

Given the widespread use of the DRASTIC model in the world and the importance of this model in evaluating vulnerability of aquifers, methods of evaluating model accuracy in differing hydrogeologic settings is an important topic. It is doubtful that the results of many DRASTIC studies have been evaluated by researchers with nitrate results using the ROC method. Attempts to change the weights and rates for model validation with nitrate analysis results can be very misleading. The results of this study showed that even where there is a minimum of sufficient data, the use of the generic DRASTIC method can provide acceptable results and there is no need to make extensive changes in the structure of the model. Therefore, there is a method available to determine the usefulness of the model output and answer the fundamental question posed by Box and Draper (1987) “All models are wrong, but some are useful; the practical question is how wrong do they have to be to not be useful." The DRASTIC model created to assess the groundwater vulnerability of the aquifer studied is useful.

In some studies, using the DRASTIC model, due to the lack of data related to the aquifer, vadose zone, and soil environment have been combined to generalize subsurface conditions (Iqbal et al. 2015; Amiri et al. 2020). This amount of generalization and over-simplification of geological conditions can have a negative impact on the model results. Conversely, in many groundwater vulnerability investigations, validation of the model results using nitrate content is an integral part of the model. While some aquifers do not have much variability of nitrate concentration data, the aquifer geological materials may still susceptible to contamination. Use of other chemical and physical parameters such as EC or sulfate can be used, but these chemical parameters may not be valid proxies for anthropogenic pollution. Sometimes the geological nature of the formations in contact with water determines the ionic and elemental content and has nothing to do with the nature of the aquifer susceptibility to pollution.

Based on Hamza et al. (2014), it is concluded that a high degree of subjectivity exists in assigning the index value ranges in a mapped area, and consequently, the type of quintile classification adopted in a particular study. It seems that an expert-centered perspective can 
be better at determining the most appropriate classification model, rather than a purely statistical perspective. Field studies of soil conditions and geological environments that are prone to pollution show some of the issues can be are real or not so.

\section{Use of Fuzzy logic to refine zonal boundaries}

In recent years, there have been many criticisms of the sharpness of the boundaries between different classes on the vulnerability map. This criticism may be inherently correct, but with the available data, there may be no definitive solution. Some researchers believe that the fuzzy method (Zadeh 1983) is the best way to better refine the boundaries. The concept of fuzzy logic involves assessment of defined classes and how to define membership within the defined classes. Zadeh (1996) used fuzzy logic to deal with language uncertainty. It is a superset of Boolean logic, which can be used to differentiate between the concepts of partial truth, and degrees of truth from "completely true" and "completely false". The function of membership with strict boundaries or classical (crisp sets) membership would assign only two classes defining non-membership and 1 being membership. In the realm of fuzzy logic, membership values can be assigned from 0 to 1 with the end members being non-membership and membership. Mohammadi et al. (2009) states that no point lies in a specific rating, but in all ratings.

When applying fuzzy-logic to DRASTIC modeling, a set of parameters are developed that are associated with linguist terms and variables. The terms are then linked to differing aspects of the hydrogeologic setting that are indicative of specific vulnerabilities to contamination. The fuzzy system then adjusts itself to the variation of the input indices. The Fuzzy Interferences System (FIS) generates a continuous contamination vulnerability function that provides clear boundaries between different boundaries (Afshar et al. 2007).

Numerous articles have been published using fuzzy methods (Huicheng et al. 1999; Afshar et al. 2007; Nobre et al. 2007; Rezaei et al. 2013; Jafari and Nikoo 2019; Pathak and Bhandary 2020; Saranya and Saravanan 2021). Some of the fuzzy logic applications have also been applied to investigations using multi-criteria decision-making methods such as AHP (Sener and Davraz 2013; Yang et al. 2017; Mallik et al. 2021). However, applied fuzzy methods still cannot eliminate the definiteness of boundaries in layers, such as occur in soil, aquifer media boundaries, and the vadose zone. Fuzzy methods applied to quantitative layers such as water depth, slope, hydraulic conductivity and net recharge can provide a mental picture of the integration of the change process. Since many data maps are extracted from equivalent curves, 
481

482

483

484

485

486

487

there is practically a definite structure in the nature of the data and only the problem form is fuzzy. However, in navigating the water wells to which a number is assigned, the lowest number can be selected as the representative of the finest sediments and the highest as the representative of the coarsest grains, and the final map can be multiplied by the selected weight of the generic DRASTIC model applied. This method is a great idea in aquifers with gradual changes of sedimentary facies, but it is a clear fact that the aquifer layers and the vadose zone and soil media are not practically homogeneous and are dependent on sedimentary paleoenvironments conditions and post-sedimentation events.

Related software has recently introduced options for fuzzy maps that can provide fuzzy outputs between zero and 1. A fuzzy map for the DRASTIC vulnerability was applied to the Sahneh aquifer for comparison to the generic DRASTIC map (Fig. 6a,b). They are moderately similar in nature, however, the value of AUC on ROC curve in this method is quite more than sharp boundaries in generic DRASTIC (AUC=0.86). The various steps and operating instructions for using GIS software to fuzzy 7 different layers are shown in Fig. 6a. Due to the fact that in the generic DRASTIC method, the algebraic multiplication of weights in rates has been used to overlap the seven layers in the fuzzy DRASTIC. This method cannot be used in a straight-forward manner for a multiplication function. In this case, Normalized DRASTIC weights for fuzzy pattern recognition model were applied (Fig. 6d). The most important reason for increasing the validity of this method compared to the generic DRASTIC approach is the gradual boundaries between different layers is more compatible with the measured nitrate concentration changes. These results showed that although fuzzification of the seven layers increases the accuracy of the model. However, because of the non-continuous nature of the A, S, I layers and practically the effects of sharp boundaries in the final map, this problem cannot be overcome by applying fuzzification. 


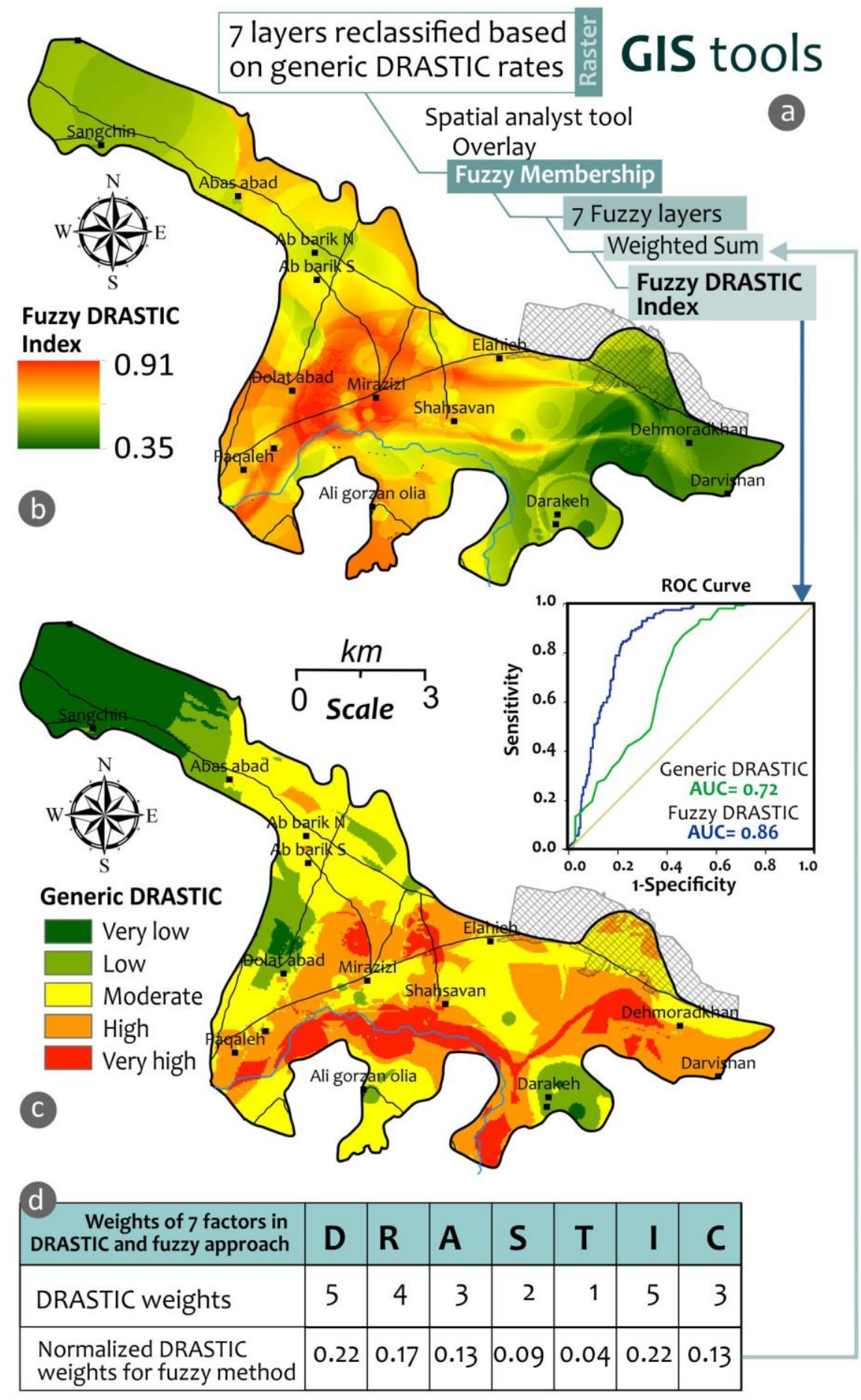

506 Fig. 6. The fuzzy-DRASTIC vulnerability of the Sahneh aquifer (a) flowchart of GIS tools 507 application and build fuzzy DRASTIC map (b) fuzzy Drastic compared to the generic 508 DRASTIC map (c), normalized DRASTIC weights for fuzzy method (d). 


\section{Conclusions}

511 Despite the controversy concerning the DRASTIC method, it is still the most common and 512 popular model for assessing the vulnerability for contamination of aquifers, especially alluvial 513 aquifers. The global expansion of this model and all its modified variants has shown that it is 514 a good measure of the ability to manage groundwater resources in terms of managing risk for 515 contamination. The results of this research showed that in an aquifer with relatively limited 516 data, very good results were obtained and verified. These results indicate the acceptable performance of this model without changing weights and rates. In different validation methods, results above $70 \%$ indicate the efficacy of the model.

Using the DRASTIC model as a minimum requirement for aquifer vulnerability assessments is justified. Use of DRASTIC generated maps can be used by governmental organizations in charge of land use and industrial development to reduce the serious consequences of aquifer pollution. This research with a flowchart can provide a step-by-step and educational approach to land use planners and operations managers to understand the methods, the usefulness of the produced map, and its weaknesses. While certain land uses could be banned in specific very high vulnerability areas, where high quality data support this map accuracy, a lesser degree of regulation could be instituted where map accuracy is in question. Methods such as full containment of hazardous materials (e.g., underground refined petroleum storage tanks) or mandatory groundwater monitoring to assess potential impacts (e.g., agricultural use) could be instituted. In must be clear, that the regulatory water management structure must be linked to the accuracy of the DRASTIC maps, particularly where sparse data are used suing the method.

It is noteworthy that the more efforts that are made to complicate the model and use multiple relationships to optimize the model, the more ambiguity occurs in the understanding and use of the final map(s) by local water-managers and decision-makers. The incompatibility of some case studies with nitrate can be considered as the inadequacy of the data used to produce some layers, because if the data are sufficient, the concordance of nitrate and other statistical methods with the generic DRASTIC model will be $>50 \%$. When the verification applied shows the DRASTIC model has a $<50 \%$ agreement with the nitrate test, then the model may not be useful as a planning tool. Because of the nature and behavior of porous media are the same based on the properties of the sediments, hydrogeological properties, and hydraulic gradients, any deviations found these fundamental properties within the context of a model 
could create a poor water-resources regulatory climate with public distrust. DRASTIC is also a universal tool, if properly and ethically applied, can support scientifically supported groundwater quality management. This should be well articulated and enforced at the beginning of the training for DRASTIC users.

\section{Ethical Approval}

Not applicable, because this article does not contain any studies with human or animal subjects.

\section{Consent to Participate}

I understand that I am free to contact any of the people involved in the research to seek further clarification and information.

\section{Consent to Publish}

I, Amjad Maleki hereby declare that I participated in the study and in the development of the manuscript title Assessment of alluvial aquifer intrinsic vulnerability by a generic DRASTIC model; a discussion on data adequacy and pragmatic results. I have read the final version and give my consent for the articl to be published in Environmental Science and Pollution Research .

\section{Authors Contributions}

All authors contributed to the study conception and design. Material preparation, data collection and analysis were performed by Kamal Taheri, Amjad Maleki and Reza Omidipour. Amjad Maleki and Jamil Bahrami supported field visits superintendence for data collection. The model validation was evaluated by Reza Omidipour. The first draft of the manuscript was written by Kamal Taheri and Thomas M. Missimer. The all authors commented on previous versions of the manuscript. All authors read and approved the final manuscript. The final English editing was by Thomas M. Missimer. 


\section{Competing Interests}

The authors have declared that no competing interests exist.

\section{Availability of data and materials}

The authors confirm that the data supporting the findings of this study are available within the article. The detailed data analyzed during the current study are available from the corresponding author on reasonable request.

\section{References}

Afshar A, Marino, M A, Ebtehaj M, Moosavi J (2007) Rule-based fuzzy system for assessing groundwater vulnerability. J Environ Engin 133(5):532-540 .

Al-Adamat R A, Foster I D, Baban S M (2003). Groundwater vulnerability and risk mapping for the Basaltic aquifer of the Azraq basin of Jordan using GIS, remote sensing and DRASTIC. Applied Geography 23(4):303-324.

Aller L, Lehr J H, Petty R, Bennett T (1987) DRASTIC: A standardized system to evaluate groundwater pollution potential using hydrogeologic settings. U.S. Environmental Protection Agency, Washington, D.C .

Amiri F, Tabatabaie T, Entezari M (2020) GIS-based DRASTIC and modified DRASTIC techniques for assessing groundwater vulnerability to pollution in Torghabeh-Shandiz of Khorasan County, Iran. Arabian Jour Geosci 13(12):1-16.

Baalousha H (2006) Vulnerability assessment for the Gaza Strip, Palestine using DRASTIC. Environ Geol 50(3):405-414 .

Babiker I S, Mohamed M A A, Hiyama T, Kato K (2005) A GIS-based DRASTIC model for assessing aquifer vulnerability in Kakamigahara Heights Gifu Prefecture, central Japan. Sci Total Environ 345:127-140

Baghapour M A, Nobandegani A F, Talebbeydokhti N, Bagherzadeh S, Nadiri A A, Gharekhani M, Chitsazan N (2016). Optimization of DRASTIC method by artificial neural network, nitrate vulnerability index, and composite DRASTIC models to assess groundwater vulnerability for unconfined aquifer of Shiraz Plain. Iran. Journal of Environmental Health Science and Engineering 14(1):1-16. 
Barbulescu A (2020) Assessing Groundwater Vulnerability: DRASTIC and DRASTIC-Like methods: A review. Water 12(5):1356.

Berhe Zenebe G, Hussien A, Girmay A, Hailu G (2020) Spatial analysis of groundwater vulnerability to contamination and human activity impact using a modified DRASTIC model in Elalla-Aynalem Catchment, Northern Ethiopia. Sustainable Water Resources Management 6:1-16.

Box G E P, Draper N R (1987) Empirical model building and response surfaces. John Wiley \& Sons, New York.

Chen W, Peng J, Hong H, Shahabi H, Pradhan B, Liu J, Zhu, A- X, Pei X, Duan Z (2018). Landslide susceptibility modelling using GIS-based machine learning techniques for Chongren County, Jiangxi Province, China. Sci Total Environ 626:1121-1135.

Chitsazan M, Akhtari Y (2009) A GIS-based DRASTIC model for assessing aquifer vulnerability in Kherran Plain. Khuzestan, Iran. Water Res Manage 23:1137-1155

Corniello A, Ducci D, Napolitano P (1997) Comparison between parametric methods to evaluate aquifer pollution vulnerability using GIS: an example in the "Piana Campana", southern Italy. In Marinos P, Koukis, G, Tsiambaos G, Stournaras G (Eds) Engineering geology and the environment, Balkema, Rotterdam, Engineering: 1721-1726

Dictionary, C. (2008) Cambridge advanced learner's dictionary. Recuperado de: https://dictionary. cambridge.org/es/diccionario/ingles/blended-learning .

Fijani E, Nadiri A A, Moghaddam A A, Tsai F T C, Dixon B (2013) Optimization of DRASTIC method by supervised committee machine artificial intelligence to assess groundwater vulnerability for Maragheh-Bonab plain aquifer. Iran. Journal of Hydrology 503:89-100.

Ghosh, R., Sutradhar, S., Mondal, P., \& Das, N. (2021). Application of DRASTIC model for assessing groundwater vulnerability: a study on Birbhum district, West Bengal, India. Modeling Earth Systems and Environment, 7(2), 1225-1239.

Hamza, M. H., \& Added, A. (2009). Validity of DRASTIC and SI vulnerability methods. In GeoSpatial Visual Analytics (pp. 395-407). Springer, Dordrecht. 
626

627

628

629

630

631

632

633

634

635

636

637

638

639

640

641

642

643

644

645

646

647

648

649

650

651

652

Hamza, M H, Added A, Rodriguez R, Abdeljaoued S, Mammou A B (2007) A GIS-based DRASTIC vulnerability and net recharge reassessment in an aquifer of a semi-arid region (Metline-Ras Jebel-Raf Raf aquifer, Northern Tunisia). J Environ Manage 84(1):12-19.

Hamza S M, Ahsan A, Imteaz M A, Rahman A, Mohammad T A, Ghazali A H (2015) Accomplishment and subjectivity of GIS-based DRASTIC groundwater vulnerability assessment method: a review. Environ Earth Sci 73(7):3063-3076.

Herlinger R Jr, Viero A (2007) Groundwater vulnerability assessment in coastal plain of Rio Grande do Sul State Brazil, using DRASTIC and adsorption capacity of soils. Environ Geol $52: 819-829$

Hua J, Hu L, Linwei F, Shuyan X (2011) Research progress of a GIS-based DRASTIC model. In: Proceedings of the 2011 Second International Conference on mechanic automation and control engineering (MACE): 2534-2526

Huicheng Z, Guoli W, Qing Y (1999) A multi-objective fuzzy pattern recognition model for assessing groundwater vulnerability based on the DRASTIC system. Hydrological Sciences Journal 44(4):611-618.

Iqbal J, Gorai A K, Katpatal Y B, Pathak G (2015) Development of GIS-based fuzzy pattern recognition model (modified DRASTIC model) for groundwater vulnerability to pollution assessment. International Journal of Environmental Science and Technology 12(10):31613174 .

Jafari S M, Nikoo M R (2019) Developing a fuzzy optimization model for groundwater risk assessment based on improved DRASTIC method. Environ Earth Sci 78(4), Article 109.

Javadi S, Kavehkar N, Mousavizadeh M H, Mohammadi K (2011) Modification of DRASTIC model to map groundwater vulnerability to pollution using nitrate measurements in agricultural areas. Journal of Agricultural Science and Technology 13(2):239-249.

Karan S K, Samadder S R, Singh V (2018). Groundwater vulnerability assessment in degraded coal mining areas using the AHP-modified DRASTIC model. Land Degradation \& Development 28(8):2351-2365. 
653

654

655

656

657

658

659

660

661

662

663

664

665

666

667

668

669

670

671

672

673

674

675

676

677

678

679

680

Khosravi K, Sartaj M., Tsai F T C, Singh V P, Kazakis N, Melesse A M, Prakash I, Bui D T, Pham, B. T. (2018). A comparison study of DRASTIC methods with various objective methods for groundwater vulnerability assessment. Sci Total Environ642:1032-1049.

Kumar P, Thakur P, Debnath S (2019). Groundwater vulnerability assessment and mapping using DRASTIC model. CRC Press .

Kura N U, Ramli M F, Ibrahim S, Sulaiman W N A, Aris A ., Tanko A I, Zaudi, M. A. (2015). Assessment of groundwater vulnerability to anthropogenic pollution and seawater intrusion in a small tropical island using index-based methods. Environ Science Pollution Res 22(2):1512-1533.

Maliva R, Missimer T (2012). Arid lands water evaluation and management. Springer, Dordrecht, The Netherlands.

Mallik, S., Bhowmik, T., Mishra, U., \& Paul, N. (2021). Local Scale Groundwater Vulnerability Assessment with an Improved DRASTIC Model. Natural Resources Research, 30(3), 2145-2160.

Merchant J W (1994) GIS-based groundwater pollution hazard assessment: a critical review of the DRASTIC model. Photogrammetric Engineering and Remote Sensing 60:1117-1127.

Metni M, El-Fadel M, Sadek S, Kayal R, Lichaa El Khoury D (2004) Groundwater resources in Lebanon: a vulnerability assessment. Int J Water Resour D 20:475-492

Mimi, Z A, Mahmoud N, Madi M A (2012) Modified DRASTIC assessment for intrinsic vulnerability mapping of karst aquifers: a case study. Environ Earth Sci 66(2):447-456.

Moghaddam A A, Fijani E (2008) Distribution of fluoride in groundwater of Maku area, northwest of Iran. Environ Geol 56:281-287

Muhammetoglu A, Keyikoglu R, Cil A, Muhammetoglu H (2019). Integrated management of pesticides in an intensive agricultural area: a case study in Altinova, Turkey. Environmental Monitoring and Assessment 191(9):1-18.

Nasri G, Hajji S, Aydi W, Boughariou E, Allouche N. Bouri S (2021) Water vulnerability of coastal aquifers using AHP and parametric models: methodological overview and a case study assessment. Arabian Jour Geosci 14(1):1-19. 
681

682

683

684

685

686

687

688

689

690

691

692

693

694

695

696

697

698

699

700

701

702

703

704

705

706

707

Nobre R C M, Rotunno Filho O C, Mansur W J, Nobre M M M, Cosenza C A N (2007)

Groundwater vulnerability and risk mapping using GIS, modeling and a fuzzy logic tool. J

Contaminant Hydrology 94(3-4):277-292.

Pacheco F A L, Pires L M G R, Santos R M B, Fernandes L S (2015). Factor weighting in DRASTIC modeling. Sci Total Environ 505:474-486.

Pathak D R, Bhandary N P (2020). Evaluation of groundwater vulnerability to nitrate in shallow aquifer using multi-layer fuzzy inference system within GIS environment. Groundwater for Sustainable Development 11, Paper 100470 .

Piscopo, G. (2001). Groundwater vulnerability map explanatory notes-Castlereagh Catchment. NSW Department of Land and Water Conservation, Australia.

Prasad R K, Singh V S, Krishnamacharyulu S K G, Banerjee P (2011) Application of DRASTIC model and GIS: for assessing vulnerability in hard rock granitic aquifer. Environ Monit Assess 176:143-155.

Rajput H, Goyal R, Brighu U (2020) Modification and optimization of DRASTIC model for groundwater vulnerability and contamination risk assessment for Bhiwadi region of Rajasthan, India. Environ Earth Sci 79(6):1-15.

Rezaei F, Safavi H R, Ahmadi A (2013). Groundwater vulnerability assessment using fuzzy logic: a case study in the Zayandehrood aquifers, Iran. Environmental Management 51(1):267-277.

Rich C C, Onasch, C . (1997). An introductory-geology laboratory exercise on ground-waterpollution potential using the DRASTIC system. J Geoscience Education 45(5):404-411 .

Rozkowski J (2010) Evaluation of intrinsic vulnerability of an Upper Jurassic karst-fissured aquifer in the Jura Krakowska (southern Poland) to anthropogenic pollution using the DRASTIC method. Geol Quat 51(1):17-26.

Rundquist D C, Peters A J, Di L, Rodekohr D A, Ehrman R L, Murray G (1991) Statewide groundwater-vulnerability assessment in nebraska using the drastic/GIS model. Geocarto International 6(2):51-58. 
Sahoo S, Dhar A, Kar A, Chakraborty D (2016). Index-based groundwater vulnerability mapping using quantitative parameters. Environ Earth Sci 75(6):522 .

Salek M, Levison J, Parker B, Gharabaghi B (2018). CAD-DRASTIC: chloride application density combined with DRASTIC for assessing groundwater vulnerability to road salt application. Hydrogeology Journal 26(7):2379-2393 .

Saranya T, Saravanan S (2021) Evolution of a hybrid approach for groundwater vulnerability assessment using hierarchical fuzzy-DRASTIC models in the Cuddalore Region, India. Environ Earth Sci 80(5):1-25 .

Sener E, Davraz A (2013). Assessment of groundwater vulnerability based on a modified DRASTIC model, GIS and an analytic hierarchy process (AHP) method: the case of Egirdir Lake basin (Isparta, Turkey). Hydrogeology Journal 21(3):701-714 .

Shepard F P (1954) Nomenclature based on sand-silt-clay ratios. J Sedimentary Petrology 24(3):151-158 .

Shirazi S M, Imran H M, Akib S (2012). GIS-based DRASTIC method for groundwater vulnerability assessment: a review. Journal of Risk Research 15(8):991-1011 .

Soyaslan İ İ (2020). Assessment of groundwater vulnerability using modified DRASTICAnalytical Hierarchy Process model in Bucak Basin, Turkey. Arabian Journal of Geosciences 13(21):1-12.

Torkashvand M, Neshat A, Javadi S, Yousefi H (2020). DRASTIC framework improvement using Stepwise Weight Assessment Ratio Analysis (SWARA) and combination of Genetic Algorithm and Entropy. Environmental Science and Pollution Research, 1-21 . https://doi.org/10.1007/s11356-020-11406-7.

Vaezihir A, Tabarmayeh M (2015) Total vulnerability estimation for the Tabriz aquifer (Iran) by combining a new model with DRASTIC. Environ Earth Sci 74(4):2949-2965 .

Warren R H P (2019). Modifying Ohio's DRASTIC ground water potential pollution model to account for karst limestone voids and sinkholes. Doctoral dissertation, The Ohio State University, Colobus, Ohio, USA. 
735 Williams, J. R., \& Kissel, D. E. (1991). Water percolation: An indicator of nitrogen-leaching 736 potential. Managing nitrogen for groundwater quality and farm profitability, 59-83.

737 Yang J, Tang Z, Jiao T, Muhammad, A. M. (2017) Combining AHP and genetic algorithms 738 approaches to modify DRASTIC model to assess groundwater vulnerability: a case study from 739 Jianghan Plain, China. Environ Earth Sci 76(12):1-16.

740 Yesilnacar E, Topal T (2005) Landslide susceptibility mapping: a comparison of logistic 741 regression and neural networks methods in a medium scale study, Hendek region 742 (Turkey). Engineering Geology 79(3-4):251-266.

743 Yin L, Zhang E, Wang X, Wenninger J, Dong J, Guo L, Huang J (2012) A GIS-based 744 DRASTIC model for assessing groundwater vulnerability in the Ordos Plateau. China 745 Environ Earth Sci: 1-15

746 Zadeh L A (1983) The role of fuzzy logic in the management of uncertainty in expert 747 systems. Fuzzy Sets and Systems 11(1-3):99-227.

748

749

750 


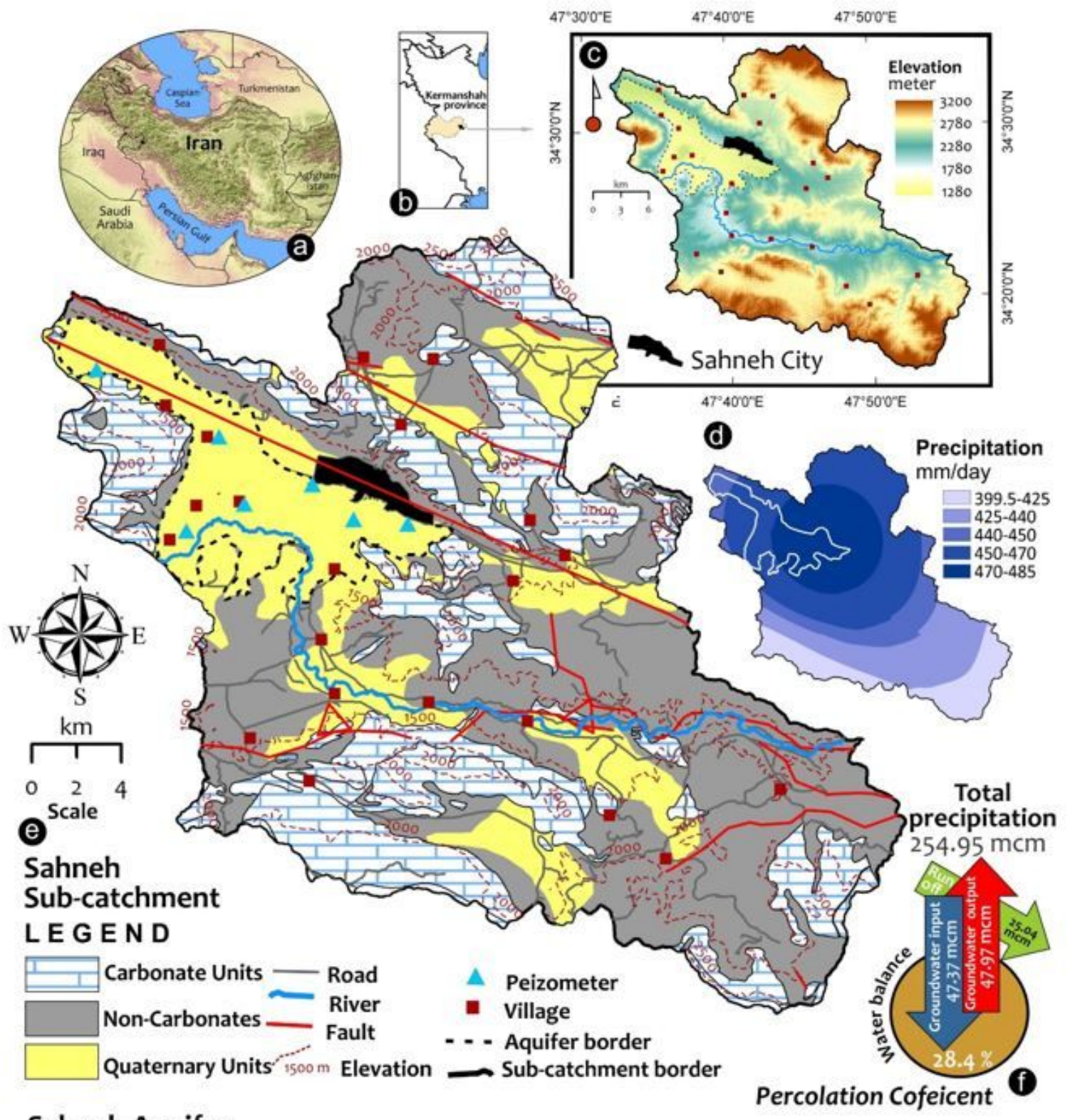

\section{Sahneh Aquifer}

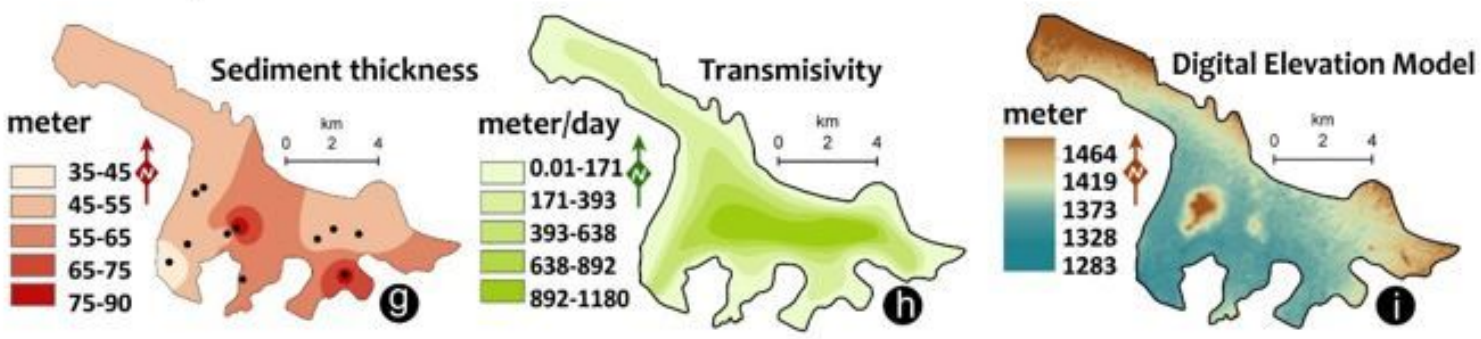

\section{Figure 1}

The location of studied area in Iran (a), Kermanshah province (b), and Sahneh Sub-catchment (c), isohytal map (d), simplified geological map and distribution of carbonate, non-carbonate formations and porous media (plain) and alluvial aquifer boundary (e), water budget summary(f), sediment thickness 
map (g), transmissivity map (h) and digital elevation model (i). Note: The designations employed and the presentation of the material on this map do not imply the expression of any opinion whatsoever on the part of Research Square concerning the legal status of any country, territory, city or area or of its authorities, or concerning the delimitation of its frontiers or boundaries. This map has been provided by the authors.

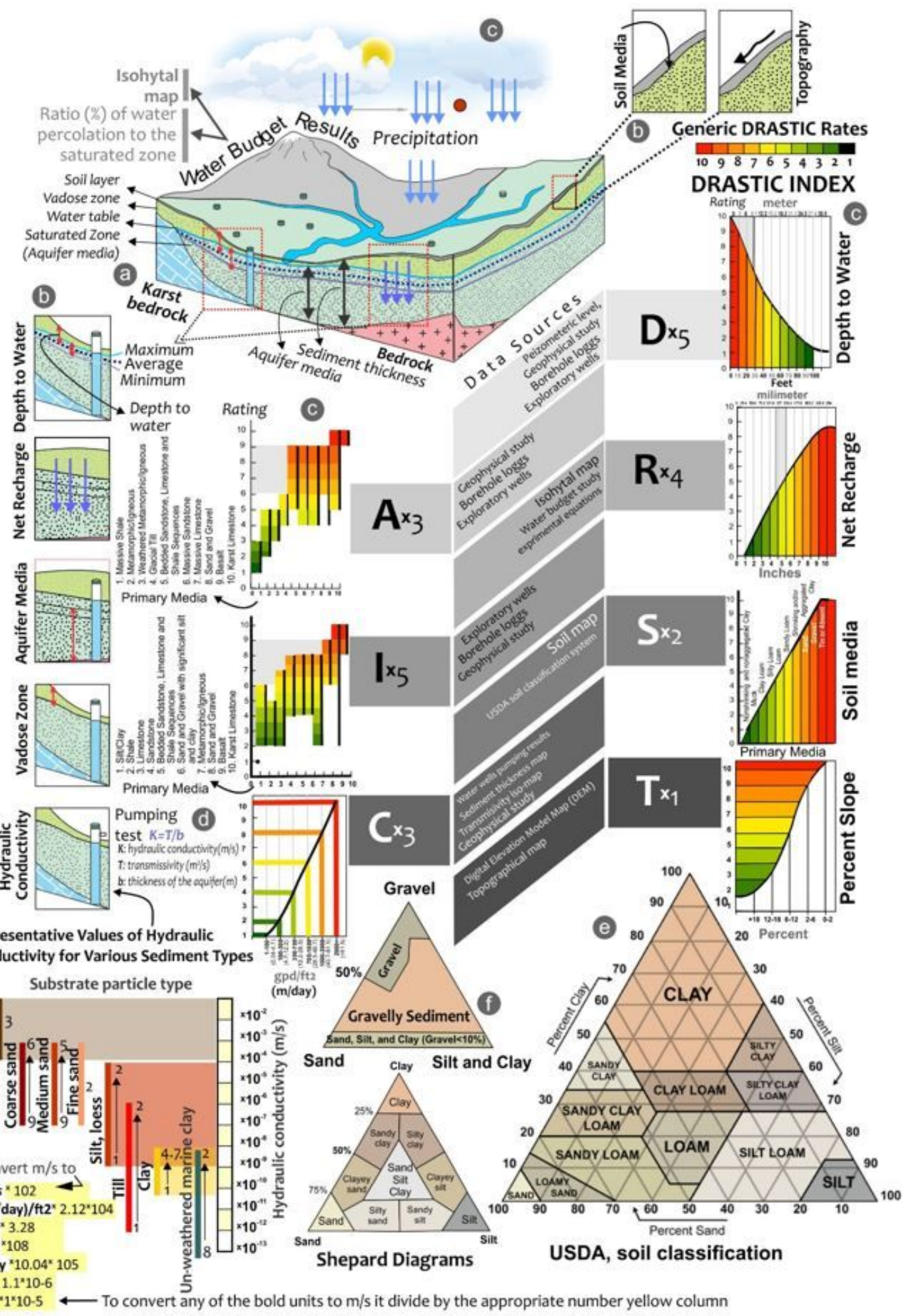

Figure 2 
a) Conceptual model of the Sahneh aquifer and important components in the evaluation of the DRASTIC model, b) seven parameters of the DRASTIC index, c) generic DRASTIC model rates for seven factors, d) pumping test components, e) USDA Soil classification, f) Separd diagrams, g), Representative values of hydraulic conductivity for various sediment types, and h) Unit conversions (Domenico and Schwartz 1990).
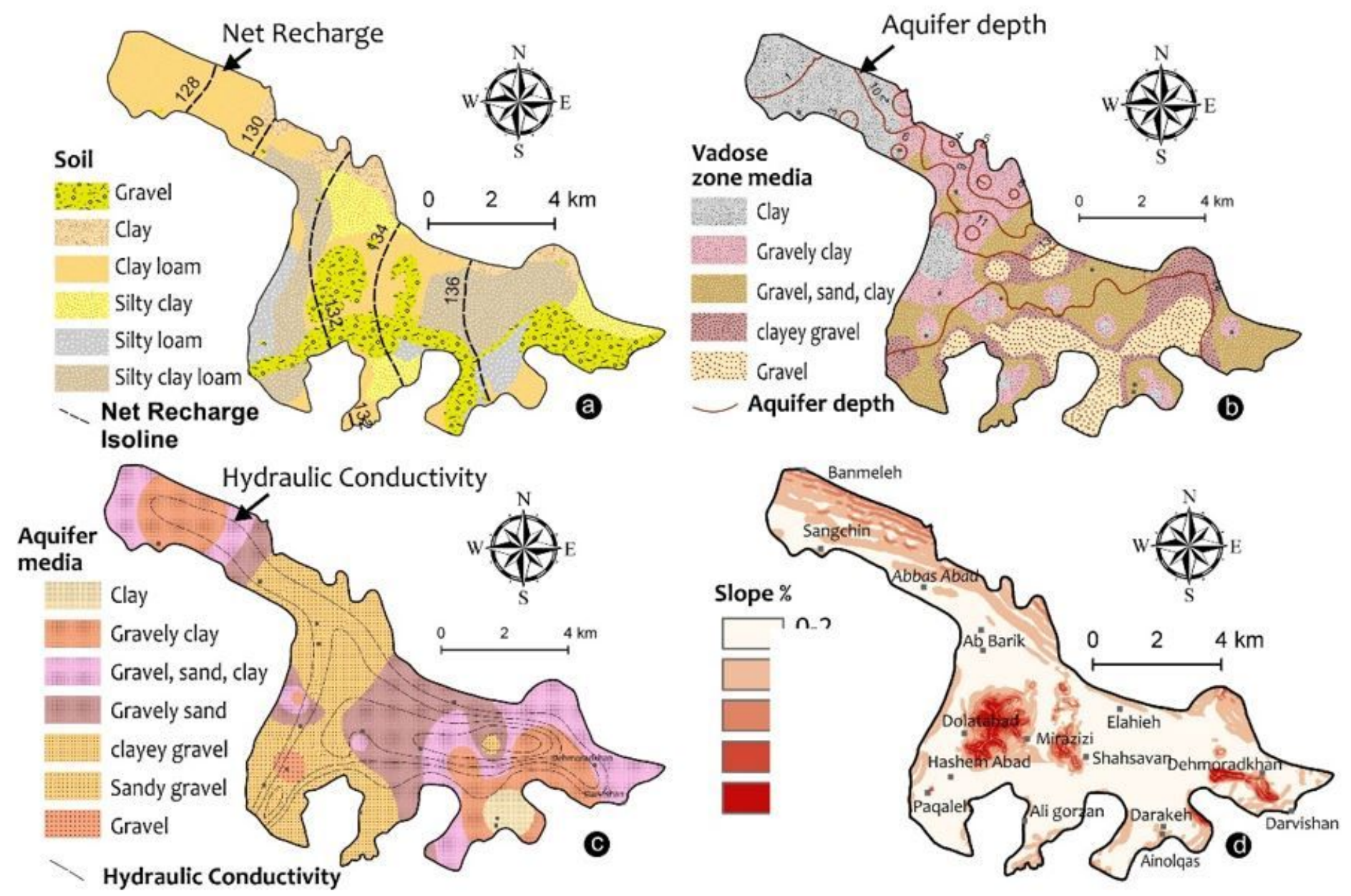

Figure 3

Seven layers of DRASTIC model; a) soil media, and net recharge, b) vadose zone media, and aquifer depth, c) aquifer media, and hydraulic conductivity, and d) slope map. Note: The designations employed and the presentation of the material on this map do not imply the expression of any opinion whatsoever on the part of Research Square concerning the legal status of any country, territory, city or area or of its authorities, or concerning the delimitation of its frontiers or boundaries. This map has been provided by the authors. 


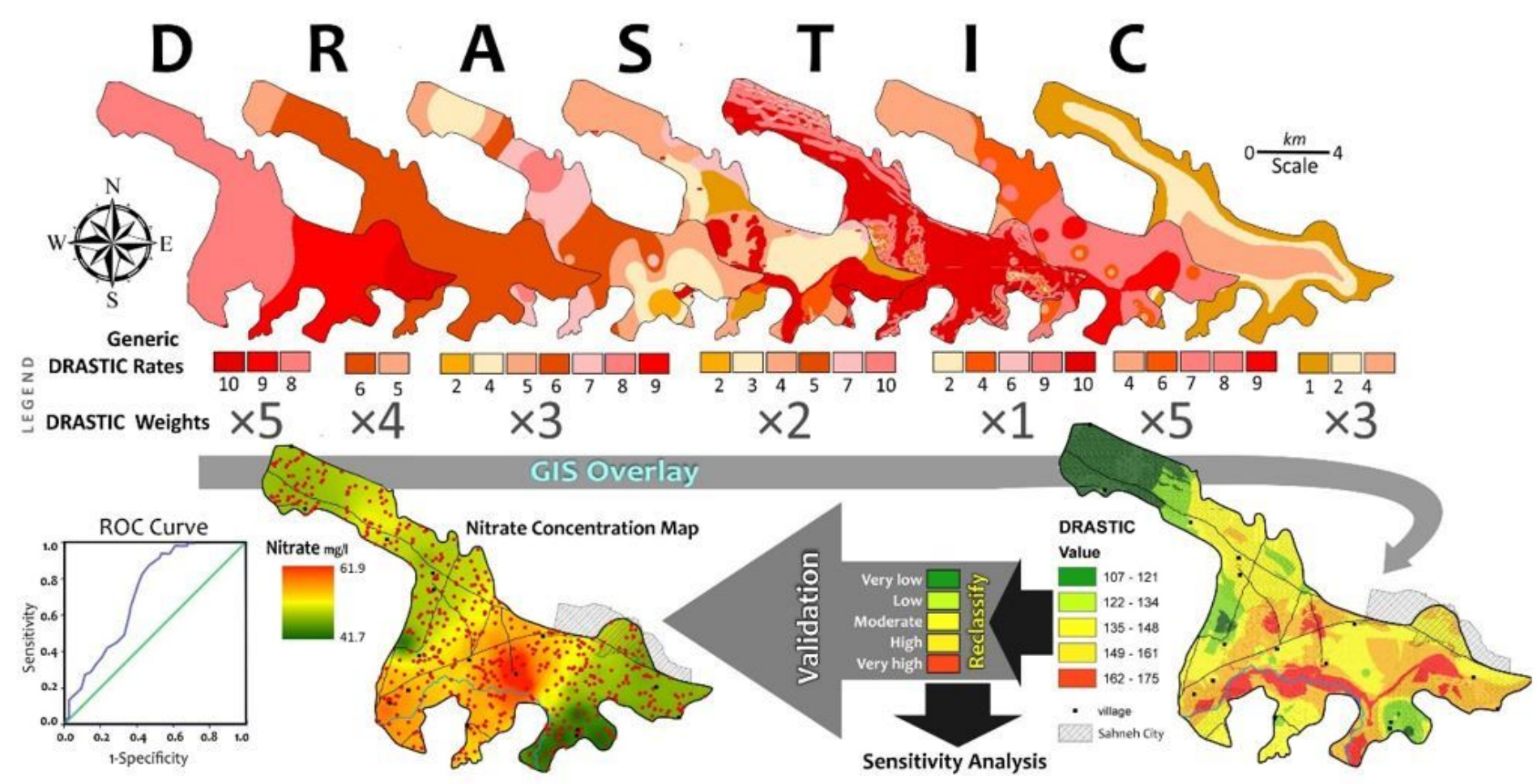

Figure 4

Flowchart of the final output model of the general DRASTIC model in the study area. Note: The designations employed and the presentation of the material on this map do not imply the expression of any opinion whatsoever on the part of Research Square concerning the legal status of any country, territory, city or area or of its authorities, or concerning the delimitation of its frontiers or boundaries. This map has been provided by the authors. 


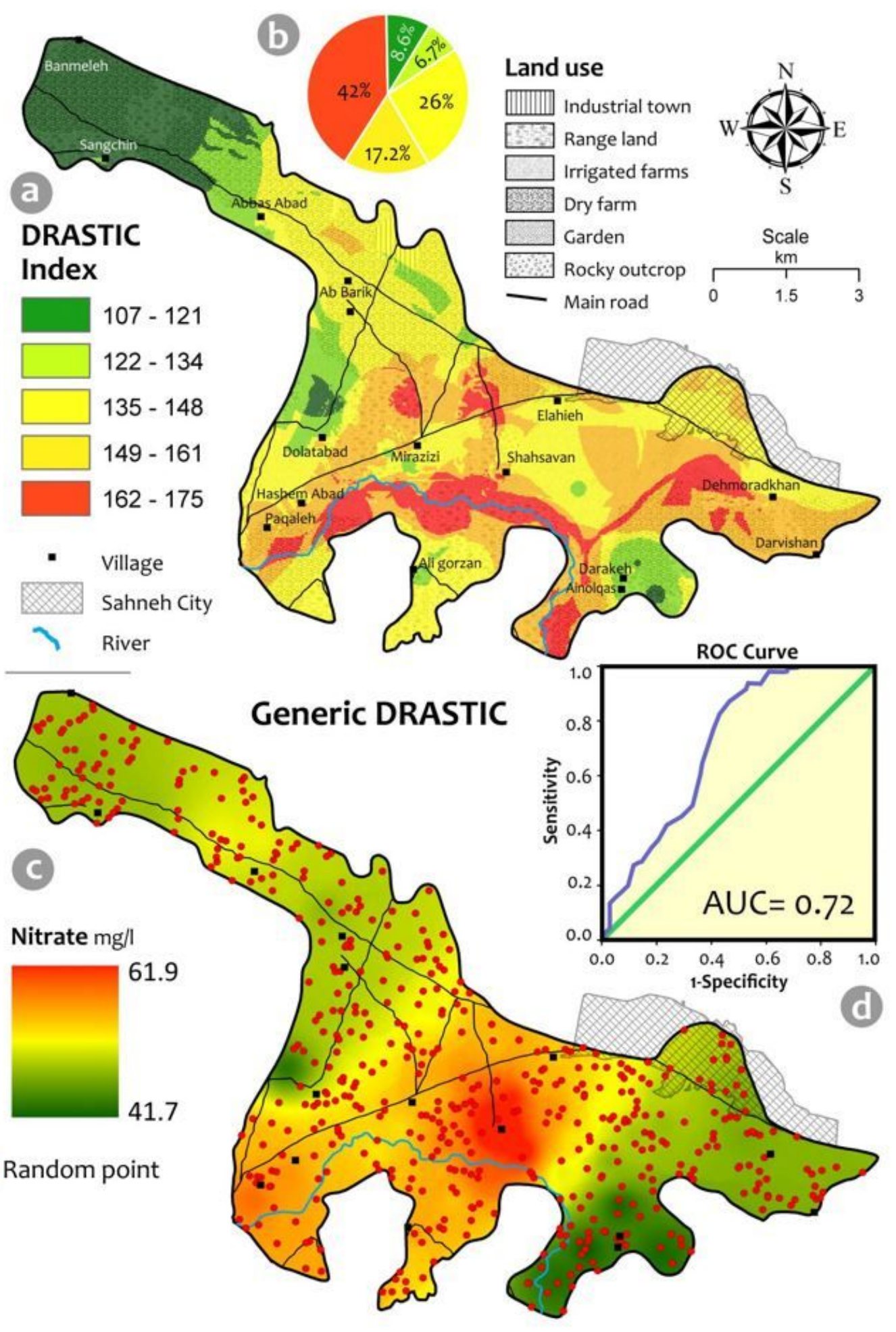

\section{Figure 5}

Nitrate analysis results (a) and its adaptation to general DRASTIC model (b) and DRASTIC with expert weights (b) linear regression (c) ROC curve with 500 random points (d) and Idrisi output (e). Note: The designations employed and the presentation of the material on this map do not imply the expression of any opinion whatsoever on the part of Research Square concerning the legal status of any country, 
territory, city or area or of its authorities, or concerning the delimitation of its frontiers or boundaries. This map has been provided by the authors.

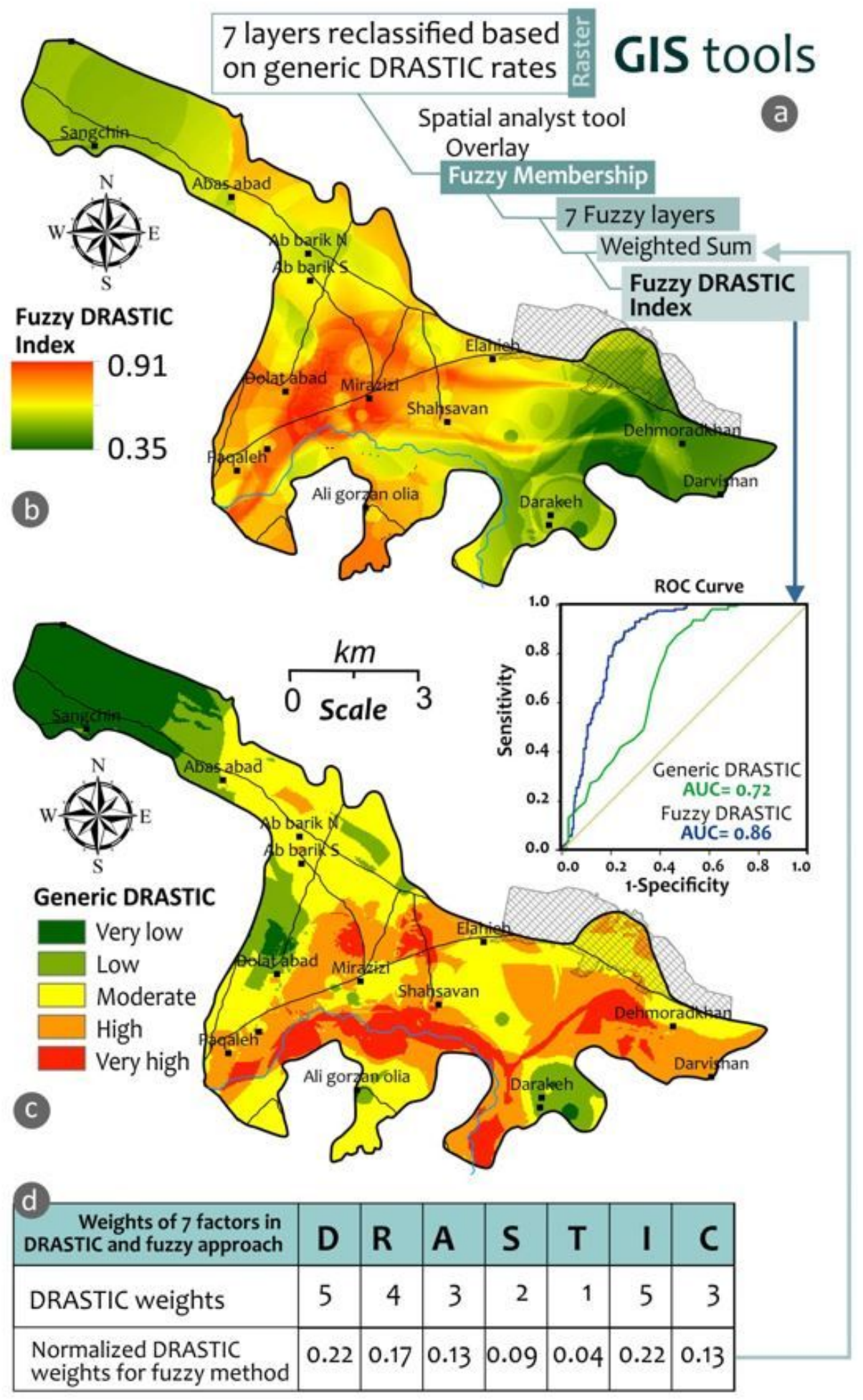

Figure 6

The fuzzy-DRASTIC vulnerability of the Sahneh aquifer (a) flowchart of GIS tools application and build fuzzy DRASTIC map (b) fuzzy Drastic compared to the generic DRASTIC map (c), normalized DRASTIC weights for fuzzy method (d). Note: The designations employed and the presentation of the material on 
this map do not imply the expression of any opinion whatsoever on the part of Research Square concerning the legal status of any country, territory, city or area or of its authorities, or concerning the delimitation of its frontiers or boundaries. This map has been provided by the authors. 